\title{
Análise Sensorial e Físico-Química de produtos elaborados à base de Soro de Leite
}

Angélica Simões FERRARI ${ }^{1}$

Nayara Ragi BALDONI ${ }^{2}$

Eveline Monteiro Cordeiro de AZEREDO ${ }^{3}$

1Universidade Federal de Alfenas-UNIFAL-MG. angelicasferrari@ hotmail.com

${ }^{2}$ Nutricionista na Secretaria de Promoção Social e Habitação de Boa Esperança-MG. nayarabaldoni@yahoo.com.br

3Universidade Federal de Alfenas-UNIFAL-MG. evelineazeredo@gmail.com

\section{Autor Correspondente:}

Prof. ${ }^{a}$ Dr. ${ }^{\text {a }}$ Eveline Monteiro Cordeiro de Azeredo

Faculdade de Nutrição

Universidade Federal de Alfenas-MG

37130-000 - Alfenas - MG - Brasil

E-mail: evelineazeredo@gmail.com

\section{Recebido em: 23/04/2013 - Aprovado em: 15/07/2013 - Disponibilizado em: 15/08/2013}

\begin{abstract}
Resumo:
O soro de leite é um subproduto obtido da fabricação de queijos, matéria prima de baixo custo, com alto valor nutricional, possuindo proteínas de alto valor biológico, além de apresentar inúmeras possibilidades de utilização para a alimentação humana. A utilização do mesmo ainda se justifica devido ao impacto ambiental causado por sua eliminação nos mananciais, por apresentar alta demanda bioquímica de oxigênio, sendo considerado um grande poluente. O objetivo do trabalho foi desenvolver preparações alimentares à base de soro de leite, buscando aquelas de mais alto consumo pela população, principalmente por crianças, e realizar análise sensorial e físico-química das mesmas a fim de verificar a aceitação e a composição centesimal, respectivamente. As preparações foram elaboradas no Laboratório de Técnica Dietética da UNIFAL-MG, e a análise sensorial piloto foi realizada com alunos e funcionários $(\mathrm{n}=50)$, utilizando-se escala hedônica de nove pontos. Foi também realizada análise sensorial em uma Escola Estadual localizada em Alfenas, MG com crianças em idade média de sete anos, utilizando-se escala hedônica facial. Procedeuse a análise da composição centesimal dos produtos, no Laboratório de Bromatologia da UNIFAL-MG. Os resultados da análise sensorial permitiram observar ótima aceitação dos produtos tanto na análise piloto como na análise com crianças. Conforme o resultado da análise da composição centesimal observou-se que o valor calórico total dos produtos foram inferiores aos produtos semelhantes tradicionalmente comercializados devido ao baixo teor de lipídeos, porém os teores de proteína foram bastante equitativos quando comparados aos produtos comerciais.
\end{abstract}

Palavras-chave: Soro de Leite. Análise Sensorial. Composição Centesimal. Bebida Láctea. Subproduto de Queijo.

\section{Sensory Analysis and Physical Chemistry of products developed based Whey}

\begin{abstract}
:
Whey is a byproduct obtained from the manufacture of cheese, low cost feedstock with high nutritional value, possessing proteins of high biological value, beyond presents numerous possibilities for use in human food. The use of it is still justified because of the environmental impact caused by its elimination in watersheds and by presentations high biochemical oxygen demand, is considered a major pollutant. The objective was to develop food preparations based on whey, seeking those with the highest consumption by the general population, especially for children, and do sensory analysis and physical chemistry of them to verify the acceptance and chemical composition , respectively. The preparations were developed in the Dietary Laboratory Technique of UNIFAL-MG, and pilot sensory analysis was performed with some students and staff $(\mathrm{n}=50)$, using the hedonic scale of nine points. Sensory analysis was also performed in a state school located in Alfenas, MG with children in an average age of 7 years, using facial hedonic scale. We proceeded to analyze the chemical composition of products, at the Laboratory of Food Science of UNIFALMG. The results of sensory analysis allowed us to observe great acceptance of products in both the pilot analysis as the analysis with children. As the result of analysis of chemical composition was observed that the total caloric value of the product were inferior to similar products traditionally marketed due to the low content of lipids, however, the protein levels were fairly equitable when compared to commercial products.
\end{abstract}

Keywords: Whey. Sensory Analysis. Chemical Composition. Milk Drink. Byproduct of Cheese. 


\section{Introdução}

De acordo com a Associação Brasileira das Indústrias de Queijo (ABIQ, 2013), o Brasil encontra-se entre os maiores produtores mundiais de leite bovino, com uma taxa anual de aumento de produção de 3 a $4 \%$, cerca de 32,5 bilhões de litros, dos quais, aproximadamente, $35 \%$ são destinados à fabricação de queijos.

O soro de leite é um subproduto da fabricação do queijo, sendo uma importante reserva proteica que pode ser utilizada para consumo humano. É obtido por meio da separação do coágulo do leite integral ou desnatado. O soro contém aproximadamente $20 \%$ das proteínas solúveis do leite, quase todo o açúcar do leite (lactose) e cerca de $50 \%$ de todos os nutrientes consumidos normalmente no leite (JELEN, 1979, citado por SILVA, 2006). Essas proteínas possuem valor nutricional elevado, contendo alto teor de aminoácidos essenciais, especialmente os de cadeia ramificada.

Evidências recentes sustentam a teoria de que as proteínas do leite, incluindo as proteínas do soro, além de seu alto valor biológico, possuem peptídeos bioativos, que atuam como agentes antimicrobianos, antihipertensivos, reguladores da função imune, assim como fatores de crescimento (SALZANO, 2002; LÖNNERDAL, 2003)

Ao lado de sua importância como fonte nutritiva, o soro de leite apresenta sério problema de poluição ambiental, pois aproximadamente $50 \%$ são lançados diretamente em curso d'água (SILVA; CARVALHO; GONÇALVES, 2003). Isso gera uma grande agressão ao meio ambiente ocasionada pelos efluentes líquidos gerados e um desperdício de um subproduto que pode ser utilizado no enriquecimento de preparações alimentares.

Diante de tais fatores, a proposta deste estudo é de grande importância econômica, ambiental e tecnológica, visto que as indústrias de laticínios podem se beneficiar pela oportunidade de aproveitamento do soro, evitando que seja lançado nos mananciais, reduzindo a agressão ao meio ambiente. Além disso, a adição do soro de leite em preparações alimentícias contribui na produção de alimentos mais nutritivos e de boa aceitação. Portanto, o presente estudo teve como objetivos a elaboração de preparações de alimentos à base de soro de leite e a realização de análise sensorial e físico-química de tais alimentos.

\section{Materiais e Métodos}

2.1. Apreciação pelo Comitê de Ética em pesquisa

O projeto foi submetido ao Comitê de Ética em pesquisa com seres humanos, e foi aprovado com o número de protocolo $101 / 2010$, sendo realizado conforme normas e 
princípios éticos que regulamentam a pesquisa com humanos.

\subsection{Amostragem}

Foram elaboradas preparações à base de soro de leite, selecionando as preparações de maior consumo pela população, sendo essas líquidas e sólidas. $\mathrm{O}$ soro de leite foi adquirido de um Laticínio da cidade de Alfenas - MG (Laticínos Alfenense).

\subsection{Preparações}

Foram escolhidas algumas preparações que foram padronizadas em relação ao teor de soro de leite utilizado, sendo duas bebidas lácteas (achocolatado e frapê de goiabada) e um bolo. A padronização e a elaboração final das preparações foram realizadas no Laboratório de Técnica Dietética da Universidade Federal de Alfenas (Unifal MG). Ressalta-se que a utilização do soro de leite em tais preparações foi como substituto total do leite.

\subsection{Análise sensorial piloto}

Foram realizados testes de análise sensorial para verificar a aceitação dos produtos. Para tal foram convidados, aproximadamente, 50 provadores, sendo alunos e funcionários da Unifal-MG para a devida degustação. Foi realizado o Teste de Aceitação utilizando a escala hedônica de nove pontos, que tem como extremidades o valor nove (9), atribuído ao termo gostei extremamente e o valor um (1), atribuído ao termo desgostei extremamente (DUTCOSKY, 1996 e MINIM, 2006). As amostras foram codificadas com algarismos de três dígitos e as análises foram realizadas em cabines individuais com luz branca no Laboratório de Técnica e Dietética da Universidade Federal de Alfenas - MG.

\subsection{Análise sensorial com crianças \\ Foram realizados testes de aceitação} dos produtos com crianças matriculadas em uma Escola Estadual localizada na cidade de Alfenas, MG, para verificar a aceitação dos produtos por crianças. As análises do achocolatado e do bolo foram feitas com 75 crianças com idade média de 7 anos. $\mathrm{O}$ frapê de goiabada foi provado por 53 crianças, na mesma faixa de idade. Foi utilizado o Teste de Aceitabilidade com escala hedônica facial, utilizando-se três tipos de faces (feliz, indiferente e triste), atribuindo-se notas 9 para face feliz, 5 para face indiferente e 1 para face triste (CHAVES, 1999).

\subsection{Composição centesimal dos produtos} elaborados

Os teores de proteínas foram obtidos pelo método de Kjeldahl segundo a metodologia da AOAC (1992), os de lipídios pelo método de Bligh Dyer (BLIGH DYER, 1959), de umidade pela determinação do Extrato Seco Total (INSTITUTO ADOLFO LUTZ, 2005) e carboidratos por diferença. As análises físico-químicas foram realizadas no Laboratório de Bromatologia e no Laboratório de Análise Nutricional e Toxicológica in vivo (Lantin) da Unifal - MG. 


\section{Resultados}

\subsection{Análise Sensorial dos Produtos}

As médias dos resultados da análise sensorial piloto e com crianças encontram-se respectivamente na Tabela 1 e no Gráfico 1.
Constatou-se nessa análise que os produtos elaborados apresentaram médias superiores a 7,00 no estudo piloto, e quantidades maiores de resposta "gostei" na análise com crianças.

Tabela 1- Médias da análise sensorial piloto

\begin{tabular}{l|c}
\multicolumn{1}{c|}{ PRODUTOS } & MÉDIAS \\
\hline BOLO & 7,94 \\
\hline BEBIDA LÁCTEA ACHOCOLATADA & 7,74 \\
\hline FRAPÊ DE GOIABADA & 8,06 \\
\hline
\end{tabular}

Fonte: $\mathrm{O}$ autor

Gráfico 1- Frequência da análise sensorial com crianças

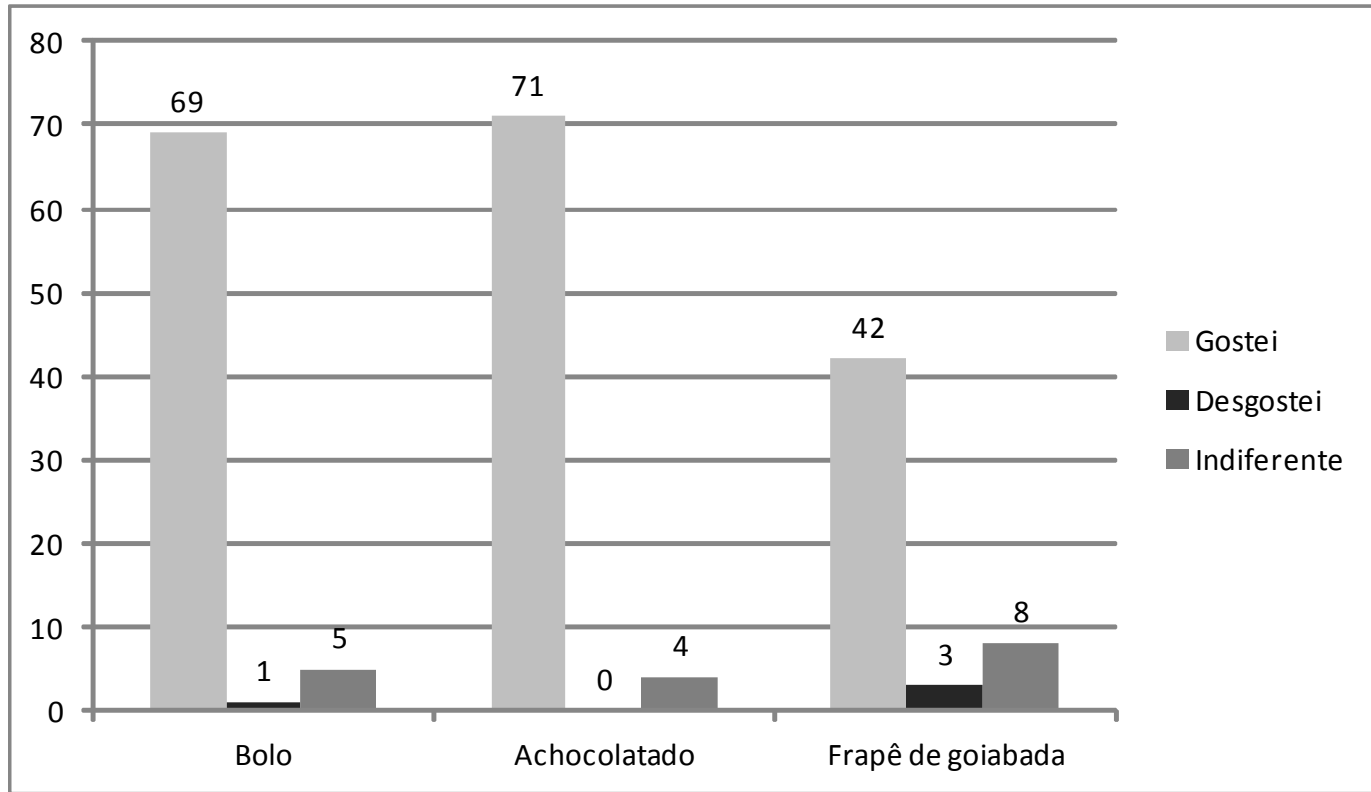

Fonte: $\mathrm{O}$ autor

\subsection{Avaliação da Composição Química}

Os teores de proteínas, lipídeos, carboidratos e o valor calórico dos produtos elaborados estão apresentados na Tabela 2.

As comparações dos valores obtidos na análise da composição centesimal, dos produtos elaborados com os produtos já existentes no mercado encontram-se nas Tabelas 3 e 4 .

Nessas comparações é possível observar que os produtos elaborados obtiveram valores menores de lipídeos e valores maiores de proteínas. 
Para tais comparações foram utilizados valores de referência dos respectivos rótulos dos produtos comercializados. Não foi realizada a comparação do frapê de goiabada, pois ainda não há produto similar no mercado.

Tabela 2- Valores médios obtidos para a composição química dos produtos elaborados

\begin{tabular}{l|c|c|c|c}
\hline \multirow{2}{*}{ PRODUTOS } & \multicolumn{4}{c}{ PARÂMETROS (em 100g) } \\
\cline { 2 - 5 } & PTN & LIP & CHO & Kcal \\
\hline BOLO & $\mathbf{7 , 1 0}$ & $\mathbf{3 , 0 8}$ & $\mathbf{5 5 , 5 5 *}$ & $\mathbf{2 7 8 , 3 2}$ \\
\hline BEBIDA LÁCTEA ACHOCOLATADA & $\mathbf{2 , 7 3}$ & $\mathbf{0 , 3 2}$ & $\mathbf{1 8 , 6 5}$ & $\mathbf{8 8 , 4}$ \\
\hline FRAPẾ DE GOIABADA & 1,68 & $\mathbf{0 , 2 2}$ & $\mathbf{1 7 , 1 8}$ & $\mathbf{7 7 , 4 2}$ \\
\hline
\end{tabular}

Fonte: $\mathrm{O}$ autor.

* O valor de referência do carboidrato foi retirado da Tabela para Avaliação de Consumo Alimentar em Medidas Caseiras (PINHEIRO et al, 1998).

Tabela 3- Comparação da composição centesimal do bolo elaborado com bolo simples de mercado

\begin{tabular}{c|c|c|c|c}
\hline \multirow{2}{*}{ PRODUTO } & \multicolumn{4}{|c}{ PARÂMETROS (em 100g) } \\
\cline { 2 - 5 } & $\begin{array}{c}\text { ENERGIA } \\
\text { (KCAL) }\end{array}$ & PROTEÍNAS & LIPÍDEOS & \multirow{2}{*}{ CARBOIDRATOS } \\
\hline ELABORADO & 278,32 & 7,10 & 3,08 & $55,55^{*}$ \\
\hline COMERCIAL** & 439 & 8,23 & 20,39 & 55,55 \\
\hline
\end{tabular}

Fonte: $\mathrm{O}$ autor

* O valor de referência do carboidrato foi retirado da Tabela para Avaliação de Consumo Alimentar em Medidas Caseiras (PINHEIRO et al, 1998).

** Os valores de referência foram coletados da Tabela para Avaliação de Consumo Alimentar em Medidas Caseiras (PINHEIRO et al, 1998).

Tabela 4- Comparação da composição química da bebida láctea achocolatada elaborada com três bebidas lácteas achocolatadas do mercado (Toddynho ${ }^{\circledR}$, Nescau ${ }^{\circledR}$ e Elegê ${ }^{\circledR}$ ).

\begin{tabular}{l|c|c|c|c}
\multirow{2}{*}{ PRODUTO } & \multicolumn{3}{|c}{ PARÂMETROS (em 100mL) } \\
\cline { 2 - 5 } & $\begin{array}{c}\text { ENERGIA } \\
\text { (KCAL) }\end{array}$ & PROTEÍNAS & LIPÍDEOS & \multirow{2}{*}{ CARBOIDRATOS } \\
\hline ELABORADO & 88,40 & 2,73 & 0,32 & 18,65 \\
\hline Toddynho® & 92,50 & 2,00 & 2,25 & 16,00 \\
\hline Nescau@ ${ }^{\circledR}$ & 96,50 & 1,95 & 3,25 & 15,00 \\
\hline Elegêe & 70,00 & 1,80 & 2,10 & 11,00 \\
\hline
\end{tabular}

Fonte: $\mathrm{O}$ autor

\section{Discussão}

É possível afirmar que as médias obtidas pela análise sensorial piloto dos três produtos elaborados foram satisfatórias, indicando boa aceitação dos mesmos, pois segundo Konkell et al (2004), médias de aceitação na escala hedônica superiores a seis demonstram valores consideráveis de aceitação e de acordo com Teixeira, Meinert e
Barbetta (1987), um alimento com nota superior a sete indica boa aceitação.

Pode-se afirmar também que os alimentos desenvolvidos à base do soro de leite são agradáveis ao paladar de crianças com idade média de sete anos, pois, a maioria delas, assinalou a face gostei quando experimentaram e avaliaram tais alimentos.

Devido à boa aceitação pelas crianças, torna-se interessante a introdução desses 
produtos na alimentação escolar, visto que além de apresentarem boa qualidade nutricional são economicamente viáveis, devido à utilização de um subproduto do queijo, geralmente descartado, que pode ser doado pelas indústrias de laticínios.

O soro de queijo é pouco aproveitado no setor tecnológico alimentício, representando ainda grande desperdício nutricional e financeiro, sendo grandes volumes enviados para nutrição de suínos ou direcionados a sistemas de tratamento de efluentes com baixa eficiência ou altos custos (SERPA; PRIAMO; REGINATTO, 2009).

De acordo com a análise da composição centesimal os produtos elaborados apresentaram quantidades de proteínas maiores aos de mercado, sendo bons nutricionalmente, pois essas proteínas são de melhor qualidade, visto que possuem alto valor biológico e são multifuncionais. Quanto aos lipídeos, há uma grande diferença entre os valores dos mesmos, sendo que os produtos elaborados apresentam menores valores quando comparados aos produtos comerciais, valorizando ainda mais os produtos que utilizam o soro de leite como base da sua composição, o que os tornam boas alternativas para consumidores que buscam um estilo de vida mais saudável, visto que segundo Pires (2010) as pessoas estão mais atentas e informadas sobre temas relacionados à saúde e bem estar. Ressaltando que Zavareze, Moraes e Salas-Mellado (2010), destacam que a adição de soro mantém ou até melhora as características de um bolo.
Vale acrescentar que os produtos avaliados apresentaram índices compatíveis aos recomendados desses nutrientes, porém torna-se mais relevante quando se avalia a qualidade das proteínas, que são de alto valor biológico, sendo essa uma das principais vantagens de sua utilização. De grande importância também é a possibilidade da substituição de uma matéria prima cara por uma de valor biológico semelhante, porém com custo mais acessível, valor nutritivo elevado e com excelente padrão de qualidade sensorial e nutricional. Esse aproveitamento é uma oportunidade de se evitar que o soro seja lançado nos mananciais, reduzindo-se a agressão ao meio ambiente.

\section{Conclusão}

Pelo fato do soro de leite ser uma matéria prima abundante, de custo reduzido, fonte de proteínas bioativas e apresentar comprovado potencial nutricional e fisiológico (PIRES, 2010), foi satisfatória a elaboração de produtos contendo este ingrediente como a base para diversas preparações.

Além disso, quando o bolo e a bebida láctea achocolatada foram comparados a outros produtos do mercado mostraram-se melhores nutricionalmente por possuírem proteínas de alto valor biológico, menor quantidade de lipídeo e baixo valor calórico, possuindo também boa aceitação e baixo custo. 
Sendo assim, torna-se evidente a grande importância dos produtos elaborados, sugerindo-se sua introdução na alimentação escolar, podendo fornecer proteínas de alto valor biológico para propiciar um adequado crescimento e desenvolvimento por meio de preparações palatáveis, práticas e de fácil acesso.

Considerando o que já foi discutido a respeito dos benefícios da utilização do soro de leite, é preciso reafirmar as alternativas viáveis para o reaproveitamento do soro, sendo de suma importância dar um destino ambientalmente correto a essa matéria prima pouco explorada no Brasil.

\section{Agradecimentos}

Esse trabalho teve o apoio da Universidade Federal de Alfenas - MG, do Laticínios Alfenense e da Escola Estadual Arlindo Silveira Filho, localizados na cidade de Alfenas - MG.

\section{Referências}

ASSOCIAÇÃO BRASILEIRA DAS

INDÚSTRIAS DE QUIEJO (ABIQ). 2013.

Disponível em: <http://www.abiq.com.br>. Acesso em 06 abr. 2013.

ASSOCIATION OF OFFICIAL AGRICULTURAL CHEMISTS. Official methods of analysis of the Association of the
Agricultural Chemists. 12 ed. Washington:

A.O.A.C., 1992.

BLIGH, E.G.; DYER,W.J. A rapid method for total lipid extraction and purification.

Can.J.Biochem.Physiol. 1959.

CHAVES, J. B. P. Práticas de Laboratório de Análise Sensorial de Alimentos e Bebidas.

Viçosa: UFV, 1999.

DUTCOSKY, S. D. Análise sensorial de

alimentos. Curitiba: Champagnat, 1996. p. 83.

INSTITUTO ADOLFO LUTZ Normas

Analíticas do Instituto Adolfo Lutz. v. 1:

Métodos químicos e físicos para análise de alimentos, 4. ed. São Paulo: IMESP, 2005, p. 833-834.

KONKELL, F.E. E COLS. Avaliação

Sensorial de doce de leite pastosos com diferentes concentrações de amido. Ciência e Tecnologia de Alimentos, v.24, n.2, 2004.

\section{LÖNNERDAL, B. Nutritional and} physiologic significance of human milk proteins. 2003.

MINIM, V. P. R. Análise sensorial: estudos com consumidores. Viçosa: Editora UFV, 2006. 
PINHEIRO, A. B. V. et al. Tabela para Avaliação de Consumo Alimentar em

Medidas Caseiras. Rio de Janeiro, 1998.

PIRES, M. H. Alternativas para o aproveitamento do soro. Rev. Indústria de

Laticínios, n. 84, p. 24-29, 2010.

SALZANO, J. I. Nutritional supplements:

practical applications in sports, human

performance and life extension. Symposium

series 007; São Paulo; 1996-2002. p.75-2002.

SERPA, L.; PRIAMO, W.L.; REGINATTO,

V. Destino Ambientalmente Correto a

Rejeitos de Queijaria e Análise de

Viabilidade Econômica. São Paulo, 2009.

SILVA, C. E. S.; CARVALHO, N. C.;

GONÇALVES, T. C. C. O desenvolvimento

do produto: Soro de Leite Bovino no

Combate à Desnutrição. Ouro Preto, 2003.

SILVA, K.; BOLINI, H. M. A. Avaliação

sensorial do sorvete formulado com produto de

soro ácido de leite bovino. Rev. Ciência e

Tecnologia de Alimentos, Campinas, p. 116-

122, jan./mar. 2006.

TEIXEIRA, E.; MEINERT, E. M.; \&

BARBETTA, P. A. Análise Sensorial de

Alimentos. Série Didática. Florianópolis:

Editora UFSC, 1987, p 18 - 102.

ZAVAREZE, E. R.; MORAES, K. S.;

SALAS-MELLADO, M. L. M. Qualidade tecnológica e sensorial de bolos elaborados com soro de leite. Rev. Ciência e Tecnologia

de Alimentos, Campinas, jan./mar. 2010. 